\title{
Three Dimensional Virtual Environments as a Tool for Development of Personal Learning Networks
}

\author{
http://dx.doi.org/10.3991/ijet.v8iS1.2365 \\ A. Nikolaou, C. Tsolakidis \\ Department of Education, University of the Aegean, Rhodes, Greece
}

\begin{abstract}
Technological advances have altered how, where, when, and what information is created, presented and diffused in working and social environments as well as how learners interact with that information. Virtual worlds constitute an emerging realm for collaborative play, learning and work. This paper describes how virtual worlds provide a mechanism to facilitate the creation and development of Personal Learning Networks. This qualitative investigation focuses on the role of three-dimensional virtual environments (3DVEs) in the creation and development of Personal Learning Networks (PLNs). More specifically, this work investigates the reasons that drive members of Education Orientated Groups (hereafter "Groups") in Second Life (SL), to adopt a technological innovation as a milieu of learning, the ways they use it and the types of learning that are occurring in it. The authors also discuss the collaborative and social characteristics of these environments which, provide access to excellence of a specific area of interest and promote innovative ideas on a global scale, through sharing educational resources and developing good educational practices without spatial and temporal constraints.
\end{abstract}

Index Terms-Three Dimensional virtual environments, informal learning, personal learning networks, Second Life.

\section{Personal LeARning Networks}

In a landscape of technological advances, web-based technologies are rapidly changing the ways of working, teaching, and learning for a broad range of individual and organizations. Digital technologies seem to create the framework, define the conditions and construct the right tools for the production, management and dissemination of knowledge [1], [2]. This constant evolution raises intensively the need for each individual to undertake the responsibility of managing their own personal and professional development by capitalizing on modern internetbased tools and services. The rapid development of Personal Learning Networks (PLNs) creates the framework to meet the increasing lifelong learning needs. The term Personal Learning Network is relatively new and the relevant literature is not extensive. Reference [3] defines PLN as a network of people with whom one is connected with the aim to learn. This is achieved through the guidance of some members that create learning opportunities, help giving answers to questions and contribute to mutual learning. The development of a PLN is based on personal choices and is a network of connections based on needs. A PLN includes: (a) tools that facilitate the networks development, (b) people who constitute the networks, (c) personal relationships, (d) connections and (e) contacts. Key elements that characterize the relationships developed between members of the network are reciprocity and trust that encourage exchanges of information with the aim of learning. PLNs describe informal learning habits and create learning opportunities through relationships and interactions. They are not social networks, as the incentive to participate in them is learning. They are referred to as the sum of social capital and connections that facilitates individuals to create their own autonomous learning environment. Each person throughout this network, serves personal learning needs which are not limited by collective goals.

Since the term PLN is newly established, it is often confused with the term "Personal Learning Environment" (PLE). According to [4], PLE refers to ways and methods used by anyone to connect and interact within his/her own PLN. It is not a software application, but an approach of how to harness technology for learning. It consists of a set of resources and tools that someone uses in his/her working and learning routine. In other words PLE describes an "educational platform" on which tools, people, communities and services form and develop PLNS PLN a person can find answers to questions or seek information as well as contribute to the development of the network. Crucial to the effectiveness of the PLN is the proper selection of the people who are joined as contacts. Through the right contacts and the offered web tools, PLNs can provide access to the excellence and leadership in a specific field worldwide [5]. Moreover PLNs are different from learning communities. PLN members do not share a common goal or a common field of knowledge and interests, as a PLN may represent either a few or many of the interests of each individual. The learning communities refer to a common field of interest, which is not applicable to PLNs [6] and [7]. In other words there is no collective intention that drives PLNs development, such as the one that exists in the learning community. A PLN is formed as the result of the individual search of the person who initially created it.

\section{THREE-DIMENSIONAL IMMERSIVE VIRTUAL ENVIRONMENTS}

Tremendous progress in Information and Communication Technology (ICT) has led to the increasing use of three-dimensional virtual worlds in many different fields of human activity. Gaining popularity, three-dimensional worlds are used particularly by the younger generation 
and a dynamic development is expected from the educational organizations in the near future [8] and [9]. Occasionally, there have been different definitions for 3DVEs or virtual worlds, depending on the emphasis given to some of their characteristics. Reference [7] reports that, although the limits of virtual reality are not distinct and are often confused with other types of graphical environments, virtual reality can be defined "as a high-tech medium, for human-computer interface, which includes real-time simulation and interactions through multiple sensor channels" Immersive 3DVEs are interactive multiuser environments. Their users interact in real time and make this environment an essential online tool for communication, socialization and learning [10]. The figure with which every user represents himself/ herself in the virtual world is called "avatar". All users of a virtual world have the sensation that they share a common space [11] and can interact with each other. Realistic representation, interactivity and representational fidelity of these environments are very important for teaching and learning. If the environment is properly designed, it is possible to attribute a fairly realistic experience with photographic accuracy and high fidelity 12]. The three-dimensional environments provide ways of contact with information that is dynamic and interactive, hence create a "sense of immersion, a perceptual and psychological sense of being within the digital environment" as reported by [13]. Further, the feeling of presence is strengthened by a sense of orientation and position in space, as people and information are organized in a more natural way in three dimensions.

The idea that three-dimensional models are more difficult to use than two-dimensional ones and that they distract users from communication is something referred to in the literature as a disadvantage of 3DVEs. Yet, the strong points seem to excel the weak ones. With synchronous and asynchronous access to a set of users from around the world, instructors and trainees of the virtual world develop relationships, leading to educational experiences [14]. Educational experiences of virtual worlds do not exist "a priori" but are generated on the ways in which users implement their ideas and act within the framework provided by the virtual environment. In other words the possibility of designing learning environments is provided which would be impossible, difficult or dangerous to be reached in real life. With proper design of the learning activities and use of simulation capabilities of 3DVEs, learners are invited to participate in learning as an experience [14]. Whether it is for entertainment or for educational purposes, modern technology of virtual worlds indicates new ways of looking at social networks and social learning environments [15].

\section{SECOND LIFE}

Even though Second Life (SL) is not a game, it has the attractiveness of a Massive Multi-users online role playing game (MMORPG). It is not a coincidence that a large number of businesses, universities and even military or religious organizations are operating in SL. SL is an immersive 3 dimensional virtual world, entirely created by its residents. Founded by Linden Lab in 2003, in January 2012 it had about 28 million registered users [16]. It is internet accessible and includes anything that human imagination can create: cities, landscapes, mountains, lakes, shops, art galleries, universities, cultural centers, business and more. Within the virtual world of SL, each user is represented by a fully customizable avatar and have access to the virtual world from anywhere at anytime. The avatar can walk, run, jump and fly. It is able to communicate with other avatars, i.e. when it speaks the rest watching it, can hear and see its lips moving. It is expected facial characteristics and expressions to be simulated, in order to express human emotions. At the same time the user can interact with surrounding people by different ways:

- hearing and speaking in voice in a public discussion

- typing in the local chat

- engaging a private dialogue with instant messages (Ims)

- sending messages (Notifications) and content (Notecards)

- making gestures to express human emotions.

In SL one could find desktop applications, web sites and files. Virtual worlds such as SL seem to represent the future of human interaction in a global networked world where users, who have grown up with digital culture, move naturally into it [17]. These digital natives quickly incorporated into the new reality, follow their codes, use new tools, and are easily acclimated to social networking sites [18]. The sense of co-presence, the collaborative features of the platform and the ability to record the activities taking place in the virtual world of SL are elements that make SL a tool for teaching and learning [19]. The literature review on the subject reports that, in these environments, the groups of users have a sense of participation and co-presence [20], develop bonds of trust [21] and a sense of personal commitment, solidarity and loyalty.

SL platform allows users to create Groups that facilitate networking providing an important tool of mass communication and discovery of common interests among members. Groups can be instruments that can help the development of virtual communities and the organization of various activities while transferring important information to colleagues, friends, trainees or other Groups. They allow people to share content as files and three-dimensional objects with other users and provide links to other Internet applications which can extend their networking capabilities [21]. As in real life, some Groups are very active and some inactive. It is possible to update and manage the plethora of activities that take place within the virtual space through alerts sent to Groups (Group Notices / Notifications), which may be attached Cards (Notecards) with links, useful addresses in SL and three dimensional objects.

\section{E-LEARNING}

It is referenced that face to face learning can no longer meet the needs of modern society for lifelong learning. The distance learning is not just a way to compensate for the lost opportunities of conventional education. It is considered as an alternative way which meets the needs of an increasing part of population, willing to expand the learning opportunities to the entire span of their life [22] and [23]. The improvement of bandwidth, the speed of data transmission, the wireless connections, the mobile internet and the development of collaborative technologies, facilitate the potential of distance learning. Further- 
more the new concept of virtuality creates the basis for a type of e-learning, in which people deal with technology in order to build their own cognitive structure. This kind of e-learning is interactive, available online and provides automatic feedback on activities undertaken by learners [24].

SL provides an environment that stimulates, since it facilitates people's communication, motivates people to collaborate and allows learners to access learning experiences. By this aspect, SL may give a new dimension to online learning [25] and [17]. It is argued that this world facilitates the access to learning, without the social loads or the physical barriers and constrains which may exist in the real world [23].

E-learning is defined as the learning that uses electronic means developed by the evolution of ICT. In another approach, the term is defined also as a dynamic process of learning which aims at a decentralized type of open learning, using interactivity that is provided by technological advances [26].

In SL three types of e-learning can be distinguished:

- complementary type, which enriches the learning obtained by other types of learning,

- exclusive type, which provides integrated programs in virtual classes provided by universities and learning organizations,

- mixed type which is the outcome of combining virtual as well as real environments.

It seems that 3 dimentional online virtual environments offer both synchronously and asynchronously learning opportunities, as well as content sharing and interactivity, which are significant factors for knowledge management [27].

\section{INFORMAL LEARNING THROUGHOUT ACTIVITIES IN SECOND LIFE}

It is generally accepted that the rate of knowledge that is produced and devalued, imposes the acquisition of learning mechanisms that can promptly respond to this changing environment. As information sources proliferate continuously on a global scale, and affect the educational scene, learners get more interested in taking in hands the privilege of controlling their learning. According to [22] there is no longer a dedicated venue where learning can occur. Self-education should be a priority for lifelong process of learning and unlearning.

Informal learning is defined as the activity that contributes to acquisition of knowledge or skills, without the presence of externally imposed educational process. It may occur beyond programs designed by educational organizations, which means that it does not require the presence of an institution [28]. Prerequisite for informal learning is the choice and the will of the person or group to become involved in it. It is mostly self-directed and refers not only to the purpose and the content of learning, but to the process of knowledge acquisition, duration and evaluation of the results. The new technologies that have created the need for continuous acquisition of knowledge and skills, seems that create the conditions for distance self-paced learning, both formal and informal. The 3DVEs, especially SL as an educational tool, engage and educate a general population worldwide. Through the Groups of SL, having characteristics of groups as reported by [29], a variety of activities can be organized with cultural or educational content [30]. Group members can choose freely where to join, in which groups they will remain as members, which activities they will participate in, taking on themselves the management of their learning.

As examples of informal learning venues in SL a plethora can be mentioned: museums, planetarium exhibitions, libraries, lectures, seminars, workshops, tours, contests, interactive immersive representations of historical sites, revivals of historical events, learning of foreign languages, participation in treasure hunts, concerts and theater performances [30].

Some of the activities organized by Groups in SL have connections with real world organizations. We could refer to some virtual museums which are copies of the respective real world ones, such as Capella Sistina, or the Splo (SploLand) one of the most popular museum in SL, created by the "real" Exploratorium in San Francisco, which includes over 100 interactive exhibitions. Additionally Spaceport Alpha (Spaceport Alpha) has no relationship or partnership with a real life museum. It is entirely created by group members, with a common interest in spaceflight. Such museums, built by amateurs, are common practice in SL, suggesting the interest of its members for open learning experiences [30]. The goals of the activities organized in the virtual space, can be information in a scientific field, practice in the construction of three-dimensional objects, acquisition of knowledge or skills involving both worlds. We could mention activities that provide learning opportunities, such as the creation of a planet, or the operation of a nuclear reactor, or even browsing in a cell or in the internal organs of an animal. In SL exhibitions can be created that would require huge resources to built and maintained in real life, not including the huge amounts of energy, effort and time that should be spent by visitors to travel to and understand the scale of e.g. our solar system, as presented in Sploland, an interactive museum exhibition. http://maps.secondlife.com/ secondlife/SploLand/155/40/101. In virtual exhibitions in $\mathrm{SL}$, visitors can interact with exhibits in such a way that is not allowed, or is not possible, in most cases in real life[31]. In particular the possibility of changing the scale of an object or the viewing angle could be mentioned. Moreover, users have the opportunity to experience situations or processes that in real life are considered dangerous or impossible, by proper simulation.

In some virtual museums, such as the International Spaceflight Museum, visitors are enabled to take a rocket and have a ride in orbit, in order to have a sense of scale and distance between planets. For example, avatars are teleported on a platform in the sky above the museum, choose the planet to sit and get into orbit, so that they can gain a sense of scale of the solar system [32]. Apart from learning opportunities many social events are organized within SL. The ability offered to users of 3DVEss to interact in real time with like minded people, consists a networking opportunity, which is a significant factor in the learning process [33]. For these reasons, many social events are organized in SL, such as dance parties, concerts, parades, art parades or competitions. In this way users can create a framework that provides socialization opportunities to a group of users, who may never, had the opportunity to be found in areas with educational content.

Second Life offers evolving learning opportunities, which are limited only by the creativity of its users. 
According to Livingstone [28] and [34], most common areas of disciplines who have used the affordances of SL is computer science, natural sciences, architecture, urban planning, graphic design, anatomy, planning, art, literature, social sciences and tourism [31]. With the tools provided by the three-dimensional virtual platform, the content becomes interactive and is delivered as an experience, while encouraging collaboration on a global scale. Moreover, the social interaction that is developed among participants seems to be an indispensable factor for engaging learning [32].

\section{LEARNING STYLES IN SECOND LIFE}

The development of instructional technology has created new perceptions of teaching and learning. The concept of pedagogy has been expanded and has been integrated into the concept of adragogy as education spreads not only in the young ages, but in all phases of human life. Moreover, it has already been created the framework for passing a new concept of "Cybergogy", which focuses on facilitating self-directed learning. This type of learning occurs within a virtual environment and is learner-centered with collaborative characteristics [35], [32] and [36].

The variety of activities in SL, seems to satisfy all three sections of [32] models, ie. cognitive, emotional and social, making almost impossible to underestimate the influence of the 3DVEs on e-learning [25]. The elements that make SL a learning platform according to [10] are:

- Content, which is produced entirely by the users and facilitated by the integrated tools, allows the construction and programming of three-dimensional objects.

- Space or the sims of SL, which users can easily change and expand at any time.

- Virtual representatives or avatars, which can be customized and have useful information to both their appearance and their profile.

- Potential for private or group chats with voice or text.

- Sense of immersion and co-presence, as well as the ability to create and share 3-dimensional objects, expand the possibilities for cooperation in relation to other digital online environments.

Literature research states that learning in SL supports successful modern learning theories applied in conventional learning environments such as: situated learning, constructivist learning, social or collaborative learning, resource based learning and problem based learning [37] and [38].

It is worth noticing that the majority of research on learning in SL, focuses on conventional learning strategies transferred from the real world. It seems to escape from many researchers that the environment of SL is mostly unconventional and is suitable for new learning experiences. This may mean that there is a lack of pedagogical approach for a wide range of new digital applications, being developed for both formal and informal learning, which are implemented in SL. The model of Kenneth [39] seems to be more responsive than other models in the ecology of learning associated with SL. The reason is that the diversity of learning strategies used in SL and the range of learning resources incorporated in it, as well as the learning objects created and diffused within or outside
SL, make ambivalent the effectiveness of the implementation of conventional learning models.

The approach of learning model proposed by ref. [39] seems to fit more than the traditional approaches (constructivist, social, etc.), as stated by ref. [37] and [38]. The complexity of the environment of SL, the number of interactions that take place, the plethora of connections and relations developed during the activities and the connections with other web applications or tools, refer to a holistic approach of learning. The proposed model appears to take account of the codes and the culture of the users involved in these innovative environments [18]. The model of ref. [39], includes six learning styles, which are listed below:

Learning by exploring: Refers to exploration of virtual places where learner can acquire knowledge. For example exploring the 3D virtual campus of NASA, learner can acquire knowledge on issues related to the expansion of the universe. Exploring the NASA virtual space, learner can raise awareness on environmental issues, such as global warming and the melting of glaciers.

Learning by collaborating: Knowledge can be the result of team work and the dynamics that are developed within virtual teams. The literature on the cooperative nature and benefits of 3DVEs is very rich.

Learning by being: It refers to learning that occurs when learners experience a situation. Role playing games are taking place successfully in virtual worlds as 3DVEs offer appropriate space for this kind of learning activities. Learning occurs through action and meaningful participation.

Learning by building: refers to the learning gained through creation. Building and programming activities promote skills related to mathematics, physics, aesthetics and perception algorithms.

Learning by championing: refers to the learning that is acquired when the members of virtual communities adopt innovative strategies, or organize activities, or establish facilities and learning environments that inform and educate the public on issues they consider important.

Learning by expressing: It can be argued that this learning is different from previous types. Previous five categories refer to learning outcomes that result directly from the 3DVEs. In this category learning focuses on representation and transfer of mentioned activities to the real world, through the web 2.0. videos, mashinima, images or texts, which refer to activities developed in the $3 \mathrm{D}$ virtual worlds, can facilitate reflection and build a body of knowledge.

\section{RESEARCH METHODOLOGY}

The purpose of this research is to investigate the role of educational SL Groups in the creation and development of PLNs. Specifically the following questions were investigated:

- What are the reasons that members of Groups use SL?

- How do they use SL for the creation and development of PLNs?

- How do they learn?

The choice of research topic arose from the personal involvement of researchers as users and members of 
Groups in SL. According to [40], when researchers are aware or have been involved or have lived the experience of the phenomenon they are studying, they find themselves in a privileged position, particularly during the interpretation of qualitative data. The qualitative method was chosen because the nature of PLNs is by definition personal. The interview was a delicate process of data mining. The decision on which strategy to follow had to do primarily with the research questions and the context within the phenomenon examined. It is considered important that the participants mentioned directly why and how were using SL for the creation and the development of PLNs. The researchers engaged in innovative digital environments had to decide, not only on the best way to collect data, but also about the communication technology to be selected, the style of the interview (strict or loose), the digital identity, and the synchronous or asynchronous process.

In a fast developing innovative field of research the generally accepted standards on methodology cannot be applied. In such a case, the typical design of a methodological framework can be considered similar to the fatal attempt to construct something solid of something fluid [41]. This seemed to be the case in this work. To overcome this problem a flexible qualitative research method was chosen based on the E-Interview Research Framework of [41]. The method proposes a cyclical model survey of online interviews.

The environment for the interview could not be separated from the virtual world where data were collected. Thus it appeared important to talk to members of the Groups directly about why and how they use SL for the development of their PLNs. Such interviews provided a process of data collection from personal experiences of the participants. The electronic interview questions moved flexibly in the same way in which communication in SL was carried out, using the tools, technology and milieu that are familiar to the Groups' members. It was also necessary to have the consent of the participants in each stage, so as to ensure that the interview is ethically correct and is carried out with respect to protection of personal data.

Our research questions helped towards the selection of the sample of participants that would meet the following criteria: (a) They should be members of a SL Group or Groups of training or educational character and free access. (b) Groups should be active during the investigation. (c) Researchers should be able to communicate with willing members in any way (email, phone, presence in social networking sites, etc). These criteria led to the selection of a nonrandom sample [42] that came from a large active SL Group, namely the Virtual Worlds Educators Roundtable (VWER). This is a group of people from geographically dispersed places. The members meet for nearly three years, every Thursday at 9:30 pm in the same place in SL at: http://maps.secondlife.com/ secondlife/BGSU\%20Community/128/110/28 (Figure 1).

The meetings included roundtable discussions with free attendance and lectures by guest speakers who are pioneers in the field of virtual environments with educational use. The number of members of VWER Group was 616 (in January 2012). In the general profile of the Group in SL, the names of the avatars of all members were mentioned. From the individual profile of each member of VWER, one could draw data (depending on availability)

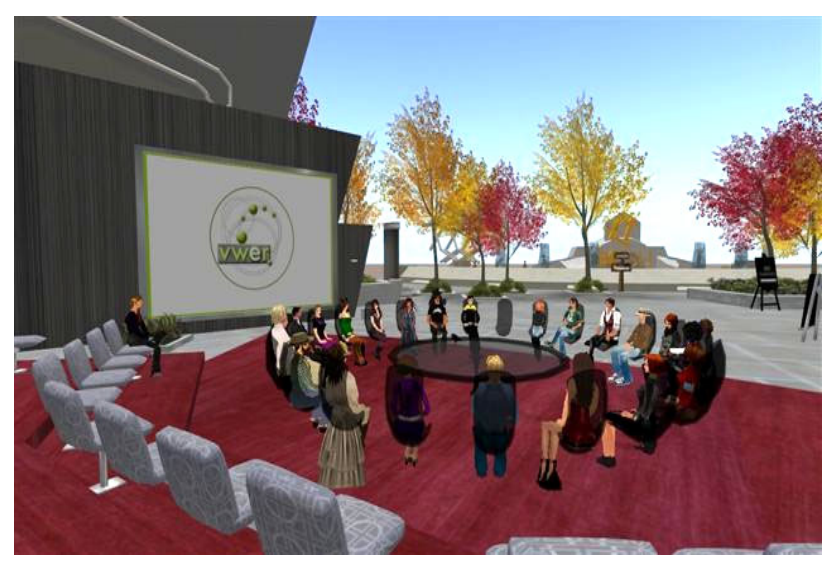

Figure 1. Meeting Place of the Group VWER

as the real name, the occupation, the personal email address, the personal webpages, blogs, wikis or the social networks they were participating. VWED has a page on the Facebook.

For survey purposes, an interview plan was developed, with ten open-ended questions. The answers were taken through written documents of Google. This fact imposed restrictions on the number of questions, ensured anonymity but did not provide the ability to raise additional data. The questionnaire was sent to the VWER Group on Facebook. Specifically it was sent to individuals who reported that were participating in recent meetings (events). Beforehand, a friendship request was sent in facebook together with a statement for the purpose of the electronic questionnaire interview. Out of the 192 persons who received the request, 38 responded. To these members, a new message was sent inviting them to answer the questions of the interview, which was attached, developed with the Google forms. In this process, 14 people responded, hence we received 14 interviews.

\section{DATA ANALYSIS}

From the data collected nearly all participants (13/14) used the tools and applications that are integrated in SL platform. Therefore they exploited the ability to chat, translate and send instant messages (IMs), notifications and information cards (Notecards). They also used the building tools to create three-dimensional objects, the programming language (script) of SL for animating and the applications of media such as web pages, presentations and videos on the $3 \mathrm{D}$ objects.

Also, apart from SL, for the publication or dissemination of educational activities and the sharing of educational resources they used blogs, wikis, facebook, Diingo, youtube, flikr, twitter and other online collaborative tools and social software. In this way they developed their PLN and created connections worldwide [43] (Figure 2).

From the responses, it appears that participation in Groups in SL, creates important networking opportunities with like minded people. In one interview it was stated:

"We can meet anytime, anywhere, without restrictions of space, time, country and money ....it's easier to meet people from the same place anywhere, anytime ... without formalities. Anybody can participate more readily than in real life and meet new members of the groups involved" (1st interview) 


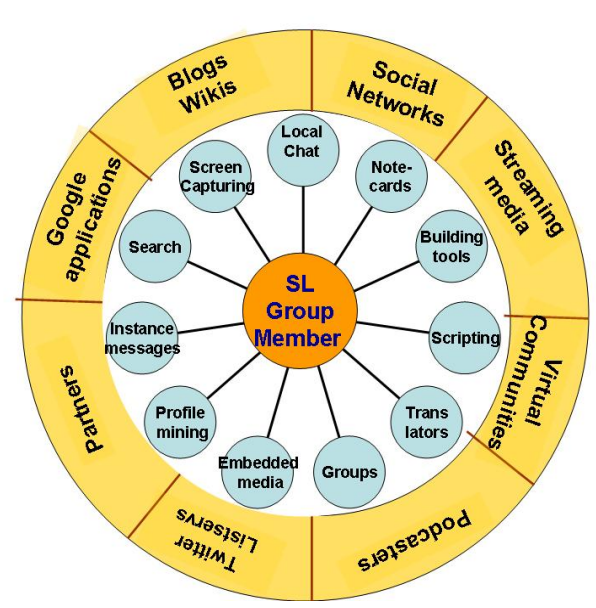

Figure 2. Use of tools by groups in SL

All participants emphasized the importance of the sense of trust and acceptance, which is enhanced through dialogue and debate. Dialogue is facilitated by multiple services provided by the platform of SL, both in the public space and private or in the space of Groups. These features are enhanced by voice conversation, movements (gestures) and animations, creating relationships that promote discussion and dialogue. These relationships are sometimes so strong that the limits between real and virtual world are unclear. Deliberations between members of Groups, deepen relationships, create conditions for real communication and networking, and are a key cause of exploitation of SL for the formation and development of PLN.

The three-dimensional virtual worlds are relatively new. Their adoption and use has to do with some idiosyncratic characteristics associated with attitudes towards change and acceptance of innovation according to the theory of adoption and diffusion of innovation [18]. For the survey participants, this innovative environment plays an important role in the development of PLNs. The fifth interview confirms with even more assertive tone the attitude to adopt innovation by members:

"The reason is that I am close to a group of people who are not afraid to experiment, to explore, to overcome limits and restrictions in order to discover the appropriate things for learning and teaching" (5th interview).

It is worth noting the ease with which mutual support and assistance is provided to members, especially to SL newcomers. This assistance was manifested in various actions as in the configuration of the avatar, the navigation in areas of common interest, the solution of technical problems, the allotment of three-dimensional objects, animation and other.

In relevant literature, the collaborative features of 3DVEs are revealed. The results ascertain that: cooperation, support and mutual help constitute the dominant culture of groups in SL. As stated in one of the interviews:

"Groups in SL, are vital for educators because of sharing of information. Not only the teams of teachers are very helpful, I've learned many tips and tricks from noneducational groups. Many educational Groups in SL are not active, while others are extremely active. I find that effective learning comes not from large conferences or formal gatherings. Most learning comes from small Groups or by postings in dialogues between groups
(Group chat). In many cases a question is asked and someone, not only is willing to answer, but also he is willing to meet you (virtually) in order to help you and he shows it".

From the capabilities offered by the 3DVE of SL, those that would really promote dialogue, facilitate discussion and remove geographical or time barriers and constraints, are: synchronous communication with text or voice, the possibility of public debate in local and private chat, and instant messaging. These tools facilitate dialogue without excluding people with impaired hearing or vision. The announcements of Groups and information trafficking in SL can be stored and be retrieved at any time. The dialogues in local chat are automatically recorded in the computer and can be studied at a later time, if needed. These characteristics refer to features of virtual learning communities and are mentioned in the third interview:

"Groups help to create communities and support communication between their members. It's easy to create and maintain Groups and what makes it even easier is the sharing of three-dimensional content, and the availability of other resources such as notecards, landmarks etc." (3rd interview).

The integrated tools that are necessary to built threedimensional objects in SL offer the opportunity to multiple users geographically dispersed to work together and edit the same object simultaneously. There are areas (sandbox) where users can freely create (build) and give movement features (animation) to objects using the script language of SL. These tools allow the development of a suitable learning environment to meet the individual requirements of users.

Many of the SL Groups develop initiatives that are related to the adoption of innovative methods and techniques, to realize goals set in real life. Such activities carried out by Groups in SL are many and can be exploratory and/or educational. Among them worth mentioning are visits to museums (Sistine Chapel, Louvre, Toys Museum, etc), collections (ancient Greek technology, computers, and musical instruments etc) at galleries of modern art. Many Groups organize experiential and collaborative activities such as role playing, treasure hunting, touring in selected virtual sites, participating in competitions for constructing three dimensional structures, foreign languages learning, attending conferences, seminars, theatrical performances, concerts etc.

Another category of activities through which creative skills can be developed in a digital environment is to construct three-dimensional objects such as buildings, landscaping, virtual labs and interactive learning objects. Also worth mentioning is that many SL Groups operate as advisory teams, offering counseling and supporting the work of non-profit organizations, researchers, activities, libraries etc.

The process by which group membership of SL contributes to the formation and development of the PLN in learning and quest for new connections is mentioned as follows:

"When since 4,5 years ago I was participating in groups in SL, I discovered the power and value of developing PLN, the value of the contacts and acquaintances I made, and the ideas that were presented, had changed learning for me. Now I know the worth of all of these and 
I have found other ways apart from groups of SL to develop and maintain my PLN: by attending webinars, and Massive Online Open Courses (MOOCs). All that is now being targeted and someone needs to know how to look for them. In SL there is the chance of discovery and creation of groups of people with similar interests and this opportunity is unexpected" (12th interview).

Summarizing we would say that members who participate in activities organized by the SL Groups create a dynamic learning network which contributes to sharing resources, content and feedback and contributes to the construction of knowledge.

\section{INFORMAL LEARNING IN SECOND LIFE}

Although understanding of informal learning is beyond the scope of this study, strong evidence emerged during the process regarding the nature of informal learning. There were findings proving that the nature of learning in SL had a social dimension. All the participants stated that some of the causes to enter and stay in-world were the networking between group members. This factor was considered very important. As stressed by the users, the continuous dialogues as well as the productive discussions were crucial for the formation of the learning milieu in SL. The activities organized by the groups, the meetings of members, the discussions with voice or text, the mutual aid and the sharing of content contributed to informal learning and to the diffusion of tacit knowledge. Each user had the ability to look for educational Groups, suited to his personal interests and learning needs according to Nikolaou and Tsolakidis [43].

Through networking, through participation and by connecting with other members, users could gain access to learning content (http://firstmonday.org/htbin/cgiwrap/bin/ ojs/index.php/fm/article/view/3496/3133 ), acquire new knowledge and contribute to the diffusion of knowledge. In other words, through groups, users came in contact with people who had a certain body of knowledge. Through interaction and socialization old knowledge had been transformed to new knowledge according to Nonaka's model.

Moreover, according to the findings of the first research axis, Group members have access to the excellence of knowledge, through the mechanisms of dialogue, networking and co-creation. The learning opportunities were proliferated, the access to the collective knowledge became easier and in that way the context of informal learning was created, which is primarily self-directed [44]. As stated by many participants, learning occurred as a result of social interaction, participation in collaborative activities and sharing of good practices [32]. The learning acquired outside the institutional framework, responded directly to the users needs and served real life aims and objectives.

Finally, some participants reported that sharing resources was an action of learning. In other cases it was reported that cooperation and sharing of content leads to learning. Through the activities realized by the Groups members, all six types of learning mentioned in the previous chapter were noticed:

a) Learning by exploring was identified in virtual museums of all kinds, in interactive art exhibitions, in ancient places replicas, such as in Pompei (Figure 3), ancient Rome, Stonehenge, or 1920's Berlin, in health information centers, in thematic tours organized by group members, in tutorial areas focused on learning skills such as Photoshop, building 3D objects, etc.

b) Learning by being took place in educational treasure hunts, in foreign languages courses and role playing for training of sellers (Figure 4), firefighters, guards, health care personnel and more.

c) Learning by collaborating occurred when group members had to participate in construction of threedimensional objects, in co-working on Google docs inworld, during workshops, meetings, conferences (Figure 5), contests, mashinima creation, landscaping, 3D art objects or installations.

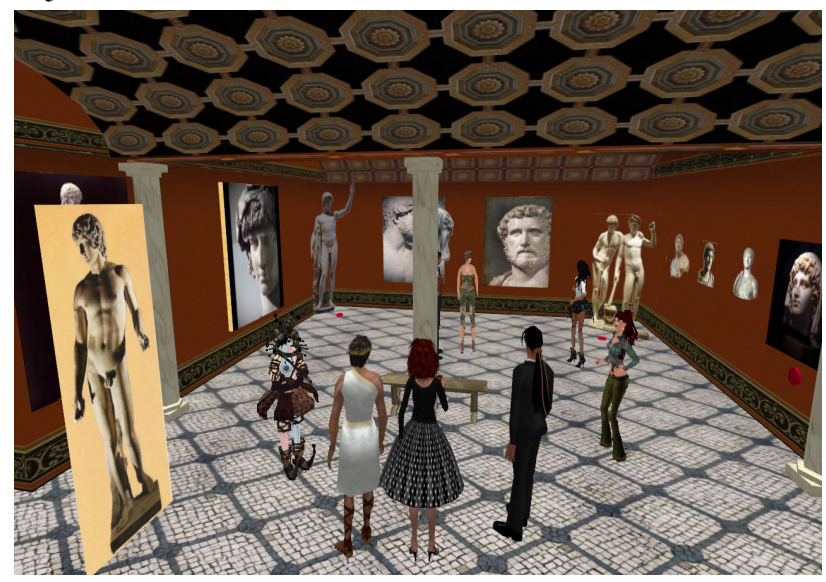

Figure 3. Visit to Pompei

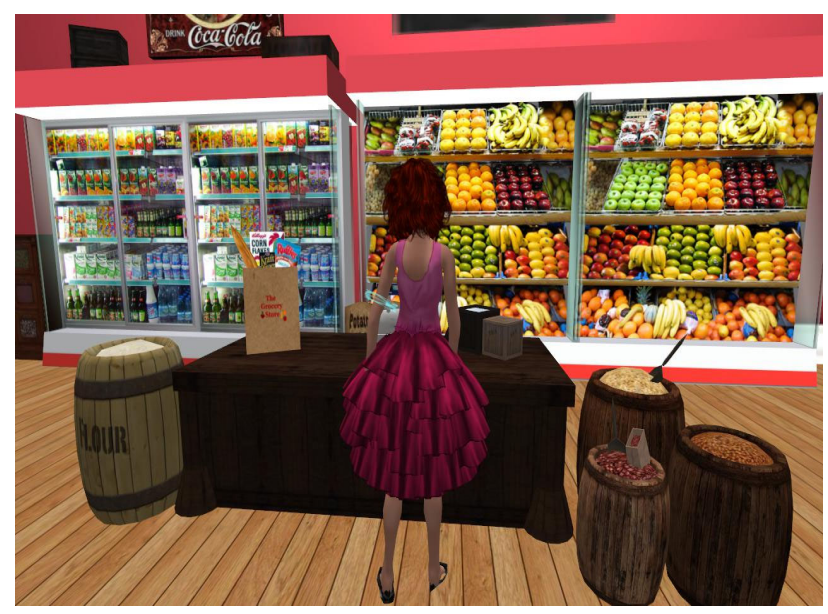

Figure 4. Sellers training

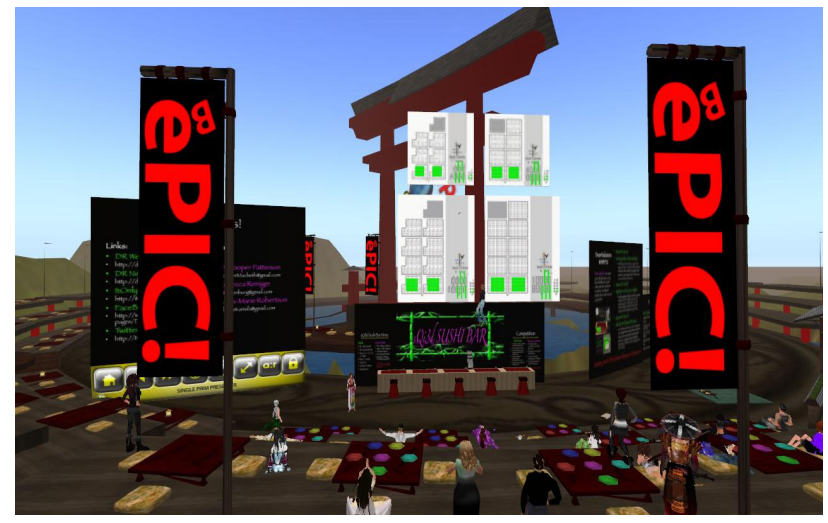

Figure 5. VWBPE Conference in SL 
d) Learning by building in SL was happening very often as 3DVE of SL is entirely constructed by its users. There were many learning opportunities during Groups activities for the participants to cooperate in order to construct the learning environments and to create $3 \mathrm{D}$ objects (Figure 6)

e) Learning by championing was happening during events organized by libraries or when non profit organizations were preparing activities supporting real life goals. It would also be mentioned the activities of religious organizations or public presentations of applied researches in virtual world, as ARVEL did.

f) Learning by expressing was happening in many activities in SL which were related to the web 2.0 applications. We could mention the mashinima created in SL and uploaded on Youtube or posted on social networks. In other cases, material taken from SL activities such as conferences, lectures, discussions, exhibitions, transcripts or pictures, had become the content of websites, blogs, tweeter or wikis (Figure 7)

By extending the dialogue and diffusing the outcome of the activity to a new era, there was more reflection which contributes to the construction of new knowledge.

\section{DISCUSSION}

This work can be considered exploratory as well as a basis for further research. Among 3DVEs, SL was selected due to the easy access by its users, the multitude of activities available in it, the large number of registered users and the ease of use for research purposes.

Although the results cannot be generalized, they give a clear picture of the role of SL Groups in forming and developing PLNs. The need for managing the rapidly produced and renewed knowledge seems to push participants to the quest of better ways for approaching it, most of which have direct relationship with various digital applications.

One could argue that the change of the way in which people adapt to the new technological environment, learn new methods, acquire new skills and have access to new educational resources, drives them into new strategies for learning using PLN beyond official and institutionalised frameworks [45] and [46]. The SL Group members through the development of PLNs seem to update their knowledge, find new opportunities for learning and achieve leadership on their professional arenas. Through their participation in virtual activities they become informed, develop contacts with others, interact, form frameworks of support and exchange educational resources [14]. Basic motive of adoption of the new environment is the positive attitude to change and innovation. Participants believe they belong to pioneers in diffusion of innovation, as early adopters, according to Rogers' model [18].

Another reason of participation is the chances for networking. This networking differs from social networking. Its motive is the interest for learning in a specific topic and the consequent need to find links with people with similar interests and research aspirations [47]. This leads to the creation of conditions for exchanging ideas, learning opportunities, enhancing promotion of good practices and sharing of educational resources, thus forming the basis for cooperation, cooperative creation and self-directed learning [14], [15] and [21].

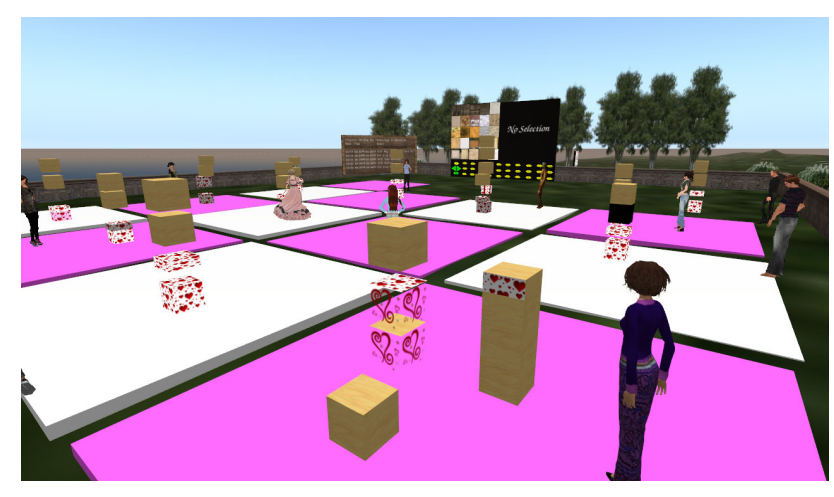

Figure 6. Building course

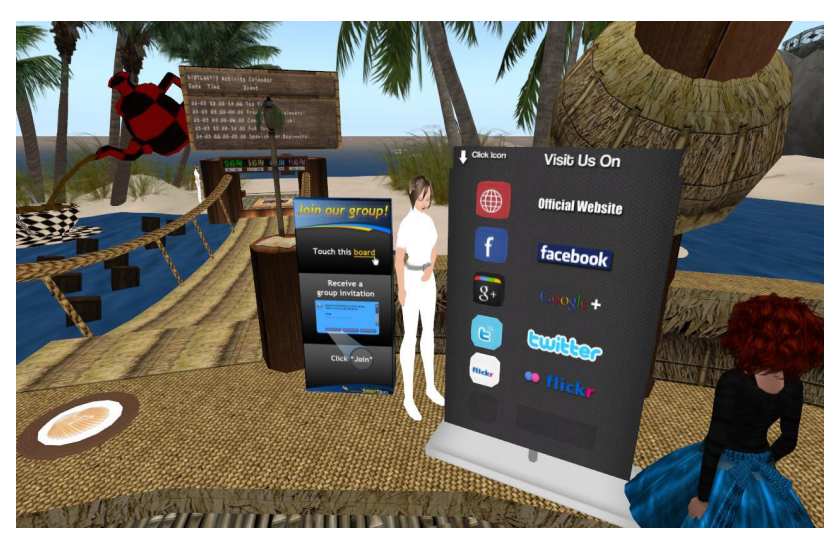

Figure 7. Connecting Web 2.0 with $3 \mathrm{D}$ virtual world

As it was characteristically referred by the participants, through the activities one could approach experts and contact leadership and excellence in any professional field without geographical, time and financial restrictions. Participation in SL Groups of educational and/or training character seems to support a constant and continuous dialogue with other members, deepens the relationship between Group members, offers a framework of cooperative actions and supports and facilitates the creation and sustainability of a PLN.

The possible ways of exploitation of SL by the members of groups are limited only by their creativity. Lectures, conferences, web teaching, meetings, counseling, participation in social, political and artistic events, cooperation in projects, visits to educational virtual paces, simulations, demonstrations, development of content and more are among the activities of the groups. It is worth noticing that the use of SL as a discussion and meeting space is the most common and favorite way of integration in educational and training activities, although it is considered that it does not exploit all the strong characteristics of the platform. This can be interpreted by two characteristics of the 3DVEs: the sense of co-presence and the potential for networking [48] and [10]. Both of these features form the social components of learning that favour sharing of content between members, cultivate a new culture of offer and sharing that creates expectations of further sharing and support, assuring that non formal learning is mainly social and participatory [49] and [26].

As the environment of SL is entirely created by its users, it has all the prerequisites to be a learning space, since each place, object, or activity can be designed from scratch. The affordances of this platform can support the appropriate "scene" and teaching material required for any 
planned educational process. The only restriction which could be mentioned is the possible limited creativity of users. As a result group members participating in SL activities contribute to self-directed learning. They seem to be able both to satisfy their personal learning needs, adopting the learning style that suits them and to undertake themselves the knowledge management creating and developing their own PLN [50] and [4].

A lot of characteristics of the 3DVEs play an important role in formulating PLN, thus a series of questions emerge that need to be further investigated as:

- What are the advantages and disadvantages of the groups that are using 3DVEs in relation to other groups that are using 2D virtual environments with respect to professional development?

- What are the best practices of planning educational activities for 3DVEs?

- What are the requirements for planning 3DVEs with respect to software, interactivity, interoperability (capability of transfer content in other 3DVEs), connection with and interoperability with $2 \mathrm{D}$ virtual environments?

In conclusion, in many cases the 3DVEs are not games, despite their gaming environment. The contribution of these environments in learning and managing knowledge seems to be an interesting prospect that is to be studied further. This work moved towards the above direction.

\section{REFERENCES}

[1] Brown, J. (2002). Growing up Digital. USDLA Journal, Vol. 16, No. 2

[2] Bennett, G. \& Jessani N., (2011). The Knowledge Translation Toolkit. International Development Research Centre

[3] Tobin, D. (1998). Personal Learning Network. Retrieved 4/1/2012 from http://www.tobincls.com/learningnetwork.htm

[4] Couros, A. (2010). Developing Personal Learning Networks for Open and Social Learning. Emerging Technologies in Distance Education pp. 109-127. Edmonton, Canada: AU Press.

[5] Torres Kompen, R, Edirishinga P., \& Mobbs R. (2008). Building Web 2.0-based Personal Learning Environments - a Conceptual Framework. Retrieved on 25/4/2012 from https://lra.le.ac.uk/bitstream/2381/4398/1/EDEN\%20ResWksp\%2 02008\%20Torres\%20Kompen\%20et $\% 20 \mathrm{al} \% 20 \mathrm{Web} \% 202.0 \% 20 \mathrm{P}$ LE\%20paper.pdf

[6] Wenger, E., Trayner, B., \& Laat, M. (2011). Promoting and Assessing Value Creation in Communities and Networks: A Conceptual Framework. Ruud de Moor Centrum Open Universiteit.

[7] Fokides E., Tsolakidis C. (2008). Virtual Reality in Education: A Theoretical Approach for Road Safety Training to Students. European Journal of Open and Distance Learning (EURODL), issue 2008/II

[8] De Freitas S. (2006) Learning in Immersive Worlds. Joint Information Systems Committee. Retrieved from http://www.jisc.ac.uk/media/documents

[9] Keany M. (2012). School Leadership 2.0 . Using Virtual Worlds to Educate Retrieved on 23/1/2012 from http://www.schoolleadership20.com/forum/topics/top-20-uses-ofvirtual-worlds-in-education

[10] Ondrejka, C. (2008). Education Unleashed: Participatory Culture, Education, and Innovation in Second Life. The Ecology of Games: Connecting Youth, Games, and Learning. Edited by Katie Salen. The John D. and Catherine T. MacArthur Foundation Series on Digital Media and Learning. Cambridge

[11] Thomas, D. \& Brown, J. ( 2009). Why Virtual Worlds Can Matter. International Journal of Learning and Media 1 (1), p. 37-49 http://dx.doi.org/10.1162/ijlm.2009.0008
[12] Barney, D. \& Lee, M. (2010). What are the Learning Affordances of 3-D Virtual Environments? British Journal of Educational Technology, Vol. 41, No. 1

[13] Krange, I., Fjuk, A., Larsen, A. \& Ludvigsen, S. (2002). Describing Construction of Knowledge through Identification of Collaboration Patterns in 3D Learning Environments. Proceedings of CSCL 2002, Boulder, Colorado, USA, January 7-11, 2002

[14] Dawley, D. (2009). Social network knowledge construction: emerging virtual world pedagogy. ON THE HORIZON, Vol. 17, N. 2, pp. 109-12 http://dx.doi.org/10.1108/10748120910965494

[15] Sköld, O. (2011). The Effects of Virtual Space on Learning: A Literature Review. First Monday [Online], Vol. 17 N. 1

[16] Tateru N. (2012). Dwell on it. Retrieved on 4/2/2012 from http://dwellonit.taterunino.net/sl-statistical-charts/

[17] Zhu, Q., Wang T. \& Jia Y. (2007). Second Life A New platform for Education. Information Technologies and Applications in Education, 2007. ISITAE '07. First IEEE International Symposium on23-25 Nov. 2007, p. $201-204$

[18] Bowers, W., Ragas, M. \& Neely, J. (2009). Assessing the Value of Virtual Worlds for Post-Secondary Instructors: A Survey of Innovators, Early Adopters and the Early Majority in Second Life. International Journal of Humanities and Social Sciences Vol.3, 1

[19] Jaeger, B. \& Helgheim, B. (2009). Role Play Study in a Purchase Management Class. Learning and Teaching in the Virtual World of Second Life: Tapir Academic Press, Trondlheim, 2009, pp. 115125.

[20] Letaief, R., Favier, M. \& Coat, F. (2006). Creativity and the Creation Process in Global Virtual Teams: Case Study of the Intercultural Virtual Project. AIM 2006. Information Systems and Collaboration: State of the Art and Perspectives, Best Papers of the 11th International Conference of the Association Information and Management (AIM), June 8-9, 2006 Luxembourg p. 242-258.

[21] Askay, D., \& Spivack, A. (2010). The Multidimensional Role of Trust in Enabling Creativity within Virtual Communities of Practice: A Theoretical Model Integrating Swift, Knowledge-Based, Institution-Based, and Organizational Trust . Proccedings. Retrieved from System Sciences (HICSS), 2010 43rd Hawaii International Conference

[22] García, L., Ruiz, M. \& Domínguez, C. ( 2008). Book Review, De la Educación a Distancia a la Educación Virtual. International Review of Research in Open and Distance Learning Vol. 9, No. 1. Retrieved http://www.irrodl.org/index.php/irrodl/article/view/529/1010

[23] Peachey A., (2008). First Reflections, Second Life, Third Place: Community Building in Virtual Worlds. Proceedings of the 1st international conference: Researching learning in Virtual Environments.

http://www.open.ac.uk/relive08/documents/ReLIVE08_conferenc e proceedings Lo.pdf

[24] Al-Ajlan, A. \& Zedan H. (2008). Why Moodle. Proceedings of 12th IEEE International Workshop on Future Trends of Distributed Computing Systems. Retrieved on 7/11/2011 from http://www.cs.helsinki.fi/u/kontulai/kurssit/tikiK10/vle/why mood le.pdf

[25] Sun, P., Tsai R., Finger G., Chen Y. \& Yeh D., (2008). What drives a Successful e-Learning? An Empirical Investigation of the Critical Factors Influencing Learner Satisfaction. Computer and Education, Volume 50, Issue 4, p.1183-1202 http://dx.doi.org/10.1016/j.compedu.2006.11.007

[26] Monahan T., McArdle, G. \& Bertolotto, M. (2008). Virtual Reality for Collaborative e-learning. Computer \& Education, Vol. 50, Issue 4, p. 1339-1353. http://dx.doi.org/10.1016/j.compedu. $\underline{2006.12 .008}$

[27] Baran, B.\& Cagiltay, K. (2006). Knowledge Management and online communities of Practice in teacher education. The Turkish Online Journal of Educational Technology V. (5), (3) Retrieved from http://www.tojet.net/volumes/v5i3.pdf\#page=12

[28] Livingstone, D. (2001). Adults' Informal Learning: Definitions, Findings, Gaps and Future Research. Centre for the Study of Education and Work, Toronto, Canada. OISE/UT. WALL Working Paper No.21, 2001. Retrieved on 16/3/2012 from https://tspace.library.utoronto.ca/bitstream/1807/2735/2/21 adultsin formallearning.pdf http://hdl.handle.net/1807/2735 
[29] Cross, P. (1998). Why Learning Communities? Why Now? ABOUT CAMPUS 1998. Conference on Transforming Campuses into Learning Communities, University of Miami. Retrieved on 15/11/2011 from http://www.nhcuc.org/pdfs/CrosSecond LifeC.pdf

[30] Bleacher, L. \& Stockman, S. (2008). Second Life: A Venue for Informal Education and Participatory Exploration. Poster session presented at the 39th Lunar and Planetary Science Conference, League City, TX. Retrieved on 12/3/2012 from http://www.lpi.usra.edu/meetings/lpsc2008/pdf/1167.pdf

[31] Penfold, P. (2009). Learning Through the World of Second LifeA Hospitality and Tourism Experience. Journal of Teaching in Travel \& Tourism. Volume 8, Issue 2-3. http://dx.doi.org/10.1080/15313220802634224

[32] Wang, M. J. (2008). Cybergogy for Engaged Learning. Journal of Open and Distance Education in China, 14(2), 14-22 http://dx.doi.org/10.4018/jdet.2008100102

[33] Urban, M., Marty, P. \& Twidale M. (2007). A Second Life for your Museum: 3D Multi-User Virtual Environments and Museums. Museums and the Web 2007: Proceedings, Toronto: Archives \& Museum Informatics, published March 1, 2007. Retrieved on 29/1/2012 from http://www.ideals.illinois.edu/bitstream/handle/2142/1619/MiSeco nd Life ill.pdf?sequence $=2$

[34] Kemp, C., Perfors, A. \& Tenenbaum, J. B. (2007). Learning over Hypotheses with Hierarchical Bayesian models. Developmental Science, $\quad 10(3), \quad 307-321 . \quad$ http://dx.doi.org/10.1111/j.14677687.2007.00585.x

[35] Carrier, I., \& Moulds, D. (2003). Pedagogy, Andragogy, and Cybergogy: Exploring Best-practice paradigm for Online Teaching and Learning. Sloan-C 9th International Conference on Asynchronous Learning Networks (ALN), Orlando, USA

[36] Wang, M. J. \& Kang, M. (2006).Cybergogy of Engaged Learning through ICT: A framework for Creating Learner Engagement. Book Chapter. Retrieved on 11/11/2011 from http://edutechwiki.unige.ch/en/Cybergogy

[37] Schmeil, A. \& Eppler, M. (2008). Knowledge Sharing and Collaborative Learning in Second Life: A Classification of Virtual 3D Group Interaction Scripts. Journal of Universal Computer Science, vol. 14, no. 3 (2008), p.665-677.

[38] Dalgarno, B. \& Lee, M. (2010). What are the Learning Affordances of 3-D Virtual Environments? British Journal of Educational Technology Vo.1 41 No 1, p. 10-32 http://dx.doi.org/10.1111/j.1467-8535.2009.01038.x

[39] Kenneth, L. (2009). The Six Learnings of Second Life: A Framework for Designing Curricular Interventions in-world. Journal of Virtual Worlds Research, 2(1), p. 3-11. Retrieved on 15/2/2012 from http://journals.tdl.org/jvwr/article/view/424/466

[40] Finlay, L. (2009). Debating phenomenological research methods. Phenomenology \& Practice, 3(1), 6-25.
[41] Salmons, J. (2011). Making Sense of Online Interviews with the E-Interview. Research Framework. Applied Research in Virtual Environments for Learning Arvel 2011 p. 14

[42] Iosifidis, Th. (2008). Qualitative research methods in social studies. Kritiki. Athens

[43] Nikolaou, A. \& Tsolakidis, C. (2012). The Role of Three Dimensional Virtual Environments in the Development of Personal Learning Networks", 15th International Conference on Interactive Collaborative Learning, Villach, Austria, September 26-28

[44] Dunn, D. (2009). An analysis of informal learning in the 21st century workplace (Doctoral Dissertation). Capella University, United States -- Minnesota. Retrieved on 20/3/2012 from https://ezproxy.royalroads.ca/login?url=http://search.proquest.com /docview/305161598? accountid $=8056$

[45] Cross R., Parker A., Prusak L., \& Bogratti S. (2001). Knowing What we Know: Supporting Knowledge Creation and Sharing in Social Networks. Organizational Dymnamics ,Vol. 30, No 2, pp.100-120 http://dx.doi.org/10.1016/S0090-2616(01)00046-8

[46] Dabbagh, N., \& Kitsantas, A. (2012). Personal Learning Environments, Social Media, and Self-regulated Learning: A Natura Formula for Connecting Formal and Informal Learning. Internet and Higher Education 15 (2012) 3-8

[47] Cail H., Sun B., Farh P., \&Ye M., (2008). Virtual Learning Services over 3D Internet: Patterns and Case Studies. IEEE International Conference on Services Computing Vol. 2, pp.213-219.

[48] Gorini, A. Gaggioli, A. Vigna, C. \& Riva, G. (2008). A Second Life for eHealth: Prospects for the Use of 3-D Virtual Worlds in Clinical Psychology. Journal of Medical Internet Research, 10(3): 21 http://dx.doi.org/10.2196/jmir.1029

[49] Livingstone, D. \& Kemp, J. (2007). Massively Multi-learner: Recent Advances in 3D Social Environments. Retrieved by http://cis.paisley.ac.uk/research/ nal/v10n2/LinvingstoneKemp.doc

[50] Rubenson, K. (2007). Determinants of Formal and Informal Canadian Adult Learning Insights from the Adult Education and Training Surveys. Gatineau, Canada: Human Resources and Social Development Canada.

\section{AUTHORS}

A. Nikolaou and C. Tsolakidis are with the Department of Education, University of the Aegean, Rhodes, Greece (anikola@freemail.gr, tsolak@aegean.gr).

This article is an extended and modified version of a paper presented at the International Conference on Interactive Collaborative Learning (ICL2012), held 26 - 28 September 2012, in Villach, Austria. Received 15 November 2012. Published as resubmitted by the authors 3 December 2012 . 